Article

\title{
Stochastic Natural Frequency Analysis of Composite Structures Based on Micro-Scale and Meso-Scale Uncertainty
}

\author{
Shufeng Zhang * ${ }^{\mathbb{D}}$ and Xun Chen \\ Science and Technology on Integrated Logistics Support Laboratory, National University of Defense Technology, \\ Changsha 410073, China \\ * Correspondence: sfzhang@nudt.edu.cn; Tel.: +86-731-8457-3396
}

Received: 6 June 2019; Accepted: 25 June 2019; Published: 27 June 2019

check for updates

\begin{abstract}
Composite structure often shows undesirably significant uncertainty in its mechanical properties, which may consequently result into large stochastic variation of its natural frequency. This study provides stochastic natural frequency analysis of typical composite structures based on micro-scale (constituent-scale) and meso-scale (ply-scale) uncertainty. Uncertainty propagation across micro-scale and meso-scale is investigated. Response surface method (RSM) based on finite element modeling is employed to obtain approximate natural frequency of structures with complex shape or boundary conditions, and mean value and standard deviation of natural frequency of composite plate and cylindrical shell are derived. Differences in natural frequency statistics of composite plates and cylindrical shells derived by considering uncertainty at different scales are quantified and discussed. Significant statistical correlation between ply elastic properties and ply density is observed, and the statistical correlation is demonstrated to lay great influence on the statistics of structure natural frequency.
\end{abstract}

Keywords: composite; stochastic; natural frequency; uncertainty

\section{Introduction}

Fibre reinforced composite material and structures are extensively used in diverse engineering applications such as aircraft, rockets, ships, wind turbines, buildings, etc. Due to complexity in material microstructure and manufacture process, composite structure often shows undesirably large uncertainty in its mechanical performance, such as structure deflection [1,2], load capacity [3,4], buckling behaviour [5,6] and dynamic response [7]. Therefore, structure design in stochastic or probabilistic approaches is especially important for composite structures [8].

Since engineering composite structures are commonly required to have natural frequencies away from the operating value to avoid structure resonance, stochastic natural frequency of composite structures has received increased attention in recent years. Oh and Librescu [9] adopted stochastic finite element method (SFEM) to investigate stochastic natural frequency of composite cantilever beams. Dey et al. [10,11] derived natural frequency statistics of composite plates by an RS-HDMR approach and later used a surrogate model. Chakraborty et al. [12] investigated stochastic free vibration behaviour of laminated composite plates using polynomial correlated function expansion and also response surface method (RSM). Tawfik et al. [13] presented a neural network-based second order reliability method to obtain probabilistic natural frequency of composite plates. Yin et al. [14] investigated stochastic variability of natural frequencies of laminated plates by modal stability procedure probabilistic approach. Singh et al. [15] provided a free vibration analysis of composite cylindrical panels with random material properties by first-order perturbation technique, and similar study is shown in [16] 
but for composite conical shell structure. It is noticed that these current studies are based on meso-scale (ply-scale) uncertainty such as uncertainty in ply elastic properties, ply orientation, ply density and thickness, and these meso-scale random variables are considered to be independent with one another. It is known that uncertainty of ply properties is essentially caused by stochastic variation of micro-scale (constituent-scale) parameters such as properties of fibre/matrix, fibre volume ratio, micro-structure, void, etc. [17]. Although probabilistic analysis based on meso-scale uncertainty takes less computation effort, uncertainty consideration started from micro-scale would provide insight into propagation of uncertainty across different scales [18] and also possible coupling between meso-scale random variables [19-24]. Still, it seems that little work has been reported about achieving comprehensive understanding on stochastic natural frequency of composite structures by considering uncertainty at different scales. Naskar et al. [25] showed difference in natural frequency statistics of composite plates derived from different scale uncertainty, but the uncertainties at different scales are somehow not connected. Therefore, it would be valuable to conduct comprehensive comparison on achieving natural frequency statistics of composite structures from meso-scale and micro-scale uncertainty, and any difference on the results would provide good indication or enlightenment to achieve complete description over uncertainty at different scales.

This study provides natural frequency analysis of typical composite structures based on micro-scale and meso-scale uncertainty. Meso-scale statistics are derived from micro-scale uncertainty by a combination of Monte-Carlo simulation and micromechanical model, and especially statistical correlation between meso-scale random variables is discussed. Response surface method (RSM) based on finite element modeling is employed to obtain approximate natural frequency of structures with complex shape or boundary condition. Statistics of natural frequencies of laminate plate and cylindrical shell are derived by a combination of Monte-Carlo simulation and the RSM. Statistics of structure natural frequency derived from different uncertainty considerations are compared and discussed.

\section{Material Statistics}

\subsection{Micro-Scale Statistics}

Statistics of mechanical and physical properties of common E-glass fibre and epoxy are shown in Table 1. Random variables considered in micro-scale mainly include $E_{f}$ (Young's modulus of fibre), $v_{f}$ (Poisson's ratio of fibre), $\rho_{f}$ (density of fibre), $E_{m}$ (Young's modulus of matrix), $v_{m}$ (Poisson's ratio of matrix), $\rho_{m}$ (density of matrix) and $V_{f}$ (fibre volume ratio). It has been experimentally shown that E-glass fibre tends to be mechanically isotropic [26]. Experimental observation on the statistics of fibre and matrix properties is generally rarely reported. In Table 1 , the coefficient of variation (standard deviation/mean value) is assumed to be $5 \%$ if a reference is not given. All micro-scale properties shown in Table 1 are assumed to follow normal distribution in this study.

Table 1. Statistics of properties of fibre and matrix.

\begin{tabular}{cccc}
\hline & Mean Value & Standard Deviation & Distribution Type \\
\hline E-Glass Fibre & & & \\
\hline$E_{f}$ & $72 \mathrm{GPa}$ & $5 \mathrm{GPa}[27]$ & Normal \\
$v_{f}$ & 0.25 & $0.05[26]$ & Normal \\
$\rho_{f}$ & $2540 \mathrm{~kg} / \mathrm{m}^{3}$ & $127 \mathrm{~kg} / \mathrm{m}^{3}$ & Normal \\
\hline Epoxy & & \\
\hline$E_{m}$ & $3.45 \mathrm{GPa}$ & $0.086 \mathrm{GPa}[27]$ & Normal \\
$v_{m}$ & 0.35 & 0.0175 & Normal \\
$\rho_{m}$ & $1100 \mathrm{~kg} / \mathrm{m}^{3}$ & $55 \mathrm{~kg} / \mathrm{m}^{3}$ & Normal \\
\hline Fibre Volume Ratio & & & Normal \\
\hline$V_{f}$ & 0.60 & 0.03 &
\end{tabular}




\subsection{Meso-Scale Statistics}

Statistics of meso-scale properties of unidirectional (UD) E-glass/epoxy are derived from micro-scale properties by a combination of Monte-Carlo simulation and bridging micromechanical model [28]. For E-glass/epoxy composite, the bridging micromechanical model is expressed as:

$$
\begin{gathered}
E_{1}=E_{f} V_{f}+E_{m} V_{m} \\
E_{22}=\frac{\left(V_{f}+V_{m} a_{11}\right)\left(V_{f}+V_{m} a_{22}\right)}{\left(V_{f}+V_{m} a_{11}\right)\left(V_{f} S_{f 22}+a_{22} V_{m} S_{m 22}\right)+V_{f} V_{m}\left(S_{m 12}-S_{f 12}\right) a_{12}} \\
v_{12}=v_{f} V_{f}+v_{m} V_{m} \\
G_{12}=\frac{\left(G_{f}+G_{m}\right)+V_{f}\left(G_{f}-G_{m}\right)}{\left(G_{f}+G_{m}\right)-V_{f}\left(G_{f}-G_{m}\right)}
\end{gathered}
$$

where $a_{11}, a_{22}, a_{12}, S_{f 11}, \ldots, S_{m 12}$ are functions of the elastic properties of fibre and matrix as given in Huang [28]; $V_{m}$ denotes matrix volume ratio $\left(V_{m}=1-V_{f}\right) . G_{m}\left(G_{f}\right)$ is the shear modulus of matrix (fibre) which is dependent on $E_{m}$ and $v_{m}\left(E_{f}\right.$ and $\left.v_{f}\right)$ due to isotropy of matrix (fibre). $E_{1}$ denotes normal modulus in the fibre direction; $E_{2}$ denotes the normal modulus in the transverse direction; $v_{12}$ denotes the in-plane major Poisson's ratio; $G_{12}$ denotes the in-plane shear modulus. In a composite material coordinate, 1 denotes fibre direction and 2 denotes transverse direction (perpendicular to fibre direction). Lamina density is derived by the rule of mixture which is written as:

$$
\rho=\rho_{f} V_{f}+\rho_{m} V_{m}
$$

In Monte-Carlo method, the accuracy $(\zeta)$ on the estimation of a parameter $P$ is expressed as [29]:

$$
\varsigma \approx \frac{s / \sqrt{N}}{\hat{P}}
$$

where $\hat{P}$ is estimation of $P, N$ is sampling number, and $s$ is standard deviation of $P$ which is estimated as:

$$
s=\sqrt{\frac{1}{N} \sum_{k=1}^{N} g\left(\mathbf{X}_{k}\right)^{2}-\left(\frac{1}{N} \sum_{k=1}^{N} g\left(\mathbf{X}_{k}\right)^{2}\right.}
$$

where $\mathrm{X}_{k}$ is the $k$-th sample of random variables, and $g\left(\mathrm{X}_{k}\right)$ is a function on $\mathrm{X}_{k}$ such as Equations (1)-(5). $\zeta$ represents the relative difference between the mathematical expectation of a group of samples and the true mean value of corresponding random variable. Equation (6) indicates that a large enough number of samples would provide very accurate estimation on random parameters in Monte-Carlo simulation. In this work, $1 \times 10^{5}$ group of samples were drawn for the micro-scale random variables listed in Table 1 and they were substituted into Equations (1)-(5) to derive statistics of meso-scale properties. According to Equation (6), the sampling number of $1 \times 10^{5}$ provides estimation accuracy on meso-scale random variables better than $0.02 \%$. The derived mean values, coefficient of variation $(\mathrm{CoV})$ and linear correlation coefficients of UD E-glass/epoxy are shown in Table 2. The probabilistic distribution of derived ply mechanical properties was determined by Kolmogorov-Smirnov and Anderson-Darling tests, and it was shown that $E_{11}, E_{22}, v_{12}, G_{12}$ and $\rho$ all follow normal distribution with a confidence level at $95 \%$. 
Table 2. The statistics of UD E-glass/Epoxy composite.

\begin{tabular}{lcccccccc}
\hline \multirow{2}{*}{$\begin{array}{c}\text { Random } \\
\text { Variables }\end{array}$} & \multicolumn{4}{c}{ Linear Correlation Coefficient } & Mean & CoV & $\begin{array}{c}\text { Experiment } \\
\text { [30] }\end{array}$ \\
\hline$E_{1}(\mathrm{GPa})$ & $\boldsymbol{E}_{\mathbf{1}}$ & $\boldsymbol{E}_{\mathbf{2}}$ & $\boldsymbol{G}_{\mathbf{1 2}}$ & $\boldsymbol{v}_{\mathbf{1 2}}$ & $\boldsymbol{\rho}$ & & & \\
$E_{2}(\mathrm{GPa})$ & 1 & & & & & 44.5 & 0.083 & 45.6 \\
$G_{12}(\mathrm{GPa})$ & 0.65 & 1 & & & & 13.2 & 0.077 & 16.2 \\
$v_{12}$ & 0.63 & 0.98 & 1 & & & 4.93 & 0.078 & 5.83 \\
$\rho\left(\mathrm{kg} / \mathrm{m}^{3}\right)$ & -0.06 & -0.10 & -0.20 & 1 & & 0.29 & 0.107 & 0.28 \\
\hline
\end{tabular}

Table 2 shows that significant statistical correlation exists between ply mechanical properties $\left(E_{1}, E_{2}, G_{12}, v_{12}\right)$, which agrees with observation in $[19,20,22]$. A new observation is that statistical correlation between ply density $(\rho)$ and ply elastic properties $\left(E_{1}, E_{2}, G_{12}\right)$ was also significant, and this correlation seems to be rarely reported or noticed in previous studies. Actually, experimental data in Huang [28] provided a clear positive correlation between $V_{f}$ (fibre volume ratio) and $E_{1}, E_{2}, G_{12}$. Since it is known that ply density is positively dependent on the $V_{f}$, the theoretically predicted positive correlation between ply density and $E_{1}, E_{2}, G_{12}$ shown Table 2 is reasonable. Statistical correlation associated with ply density may affect stochastic vibration of composite structures as structure vibration is known to be mass dependent. Studies in later sections will demonstrate the effect of statistical correlation between $E_{1}, E_{2}, G_{12}$ and $\rho$ on the stochastic free vibration of composite structures.

\section{Analysis of Stochastic Natural Frequency}

\subsection{Laminated Plate}

In this work, stochastic natural frequency of several different configurations of laminated plates subjected to different boundary conditions as listed in Table 3 was investigated, including cross-ply laminate, angle-ply laminate, quasi-isotropic laminate and laminate of random ply orientations. For each laminate configuration, statistics of first order natural frequency were derived in three scenarios: (a) considering micro-scale uncertainty of constituent material properties as listed in Table 1, termed in short as 'micro-scale uncertainty'; (b) considering meso-scale uncertainty as listed in Table 2, and their statistical correlation was also considered, termed in short as 'correlated meso-scale uncertainty'; (c) considering meso-scale uncertainty of ply properties as listed in Table 2, but the statistical correlation between ply mechanical properties and also the density was neglected, termed in short as 'independent meso-scale uncertainty'. The flowchart of calculation process of stochastic natural frequency by considering the three different scenarios of uncertainty is shown in Figure 1. It is important to notice that most current studies (as introduced in Section 1) were based on 'independent meso-scale uncertainty', and it is necessary to discuss whether 'independent meso-scale uncertainty' provides reasonable estimation on the statistics of resonance frequency of composite structures.

Table 3. Laminate plate configurations.

\begin{tabular}{lllll}
\hline No. & Ply Thickness & Ply Orientation & Size & Boundary Condition \\
\hline Laminate 1 & $0.45 \mathrm{~mm}$ & $(0 / 90)_{4}$ & $0.6 \times 0.2 \mathrm{~m}$ & Simply supported \\
Laminate 2 & $0.45 \mathrm{~mm}$ & {$\left[( \pm 60)_{2}\right] \mathrm{s}$} & $0.6 \times 0.2 \mathrm{~m}$ & Simply supported \\
Laminate 3 & $0.45 \mathrm{~mm}$ & {$[0 / \pm 45 / 90] \mathrm{s}$} & $0.6 \times 0.2 \mathrm{~m}$ & Clamped \\
Laminate 4 & $0.45 \mathrm{~mm}$ & {$[15 / 45 / 60 / 90 / 30 / 0 / 10 / 20]$} & $0.6 \times 0.2 \mathrm{~m}$ & Clamped \\
\hline
\end{tabular}


(a) Micro-scale uncertainty

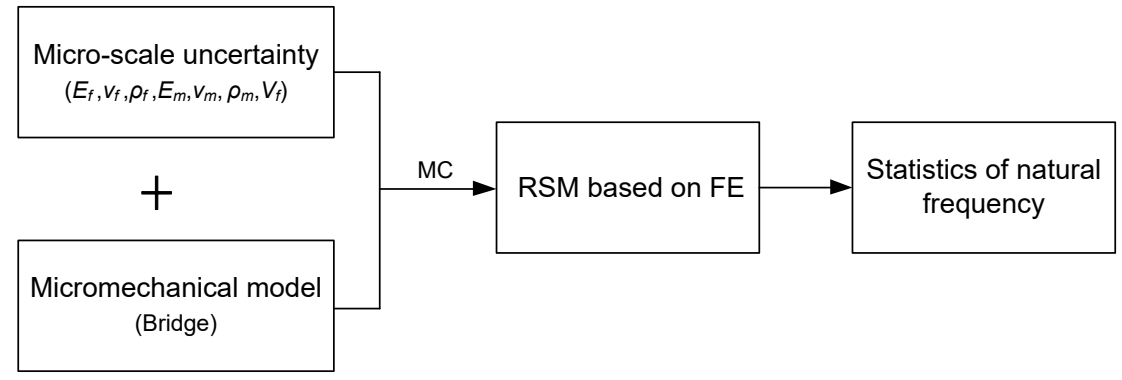

(b) Correlated meso-scale uncertainty

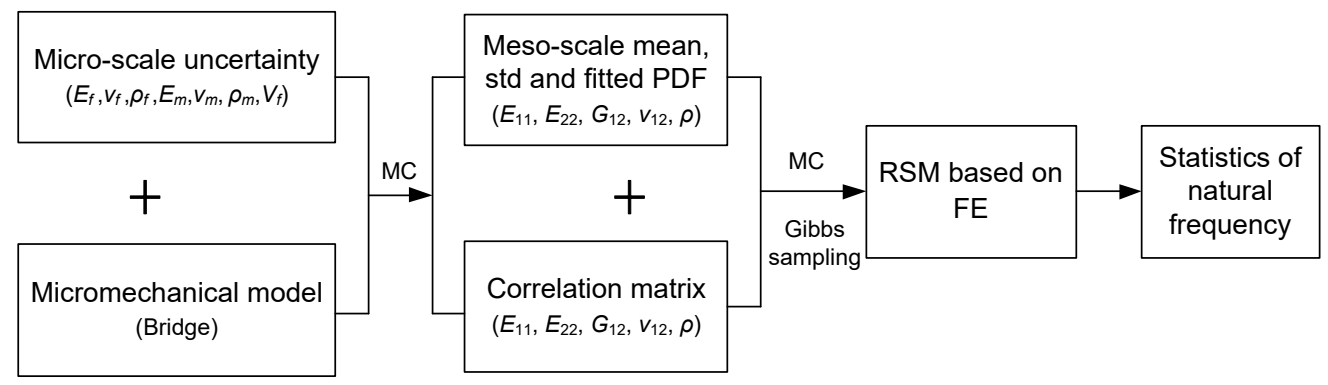

(c) Independent meso-scale uncertainty

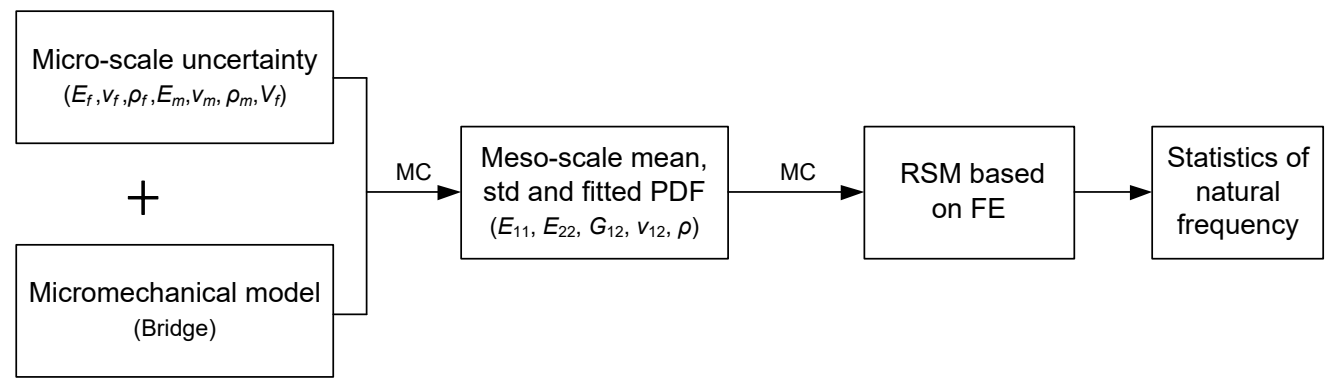

Figure 1. Flowchart of calculation of natural frequency statistics by different uncertainty consideration.

The statistics of first order natural frequency were derived by a combination of Monte-Carlo simulation and FE modeling. Four-node linear-elastic shell element (Shell181 in Ansys 14.5) is used to model the laminate. A mesh convergence study was conducted, which showed that a mesh size of $0.01 \times 0.01 \mathrm{~m}$ provided a convergent solution on the first order natural frequency. Considering heavy computation cost of direct Monte-Carlo simulation on FE modeling, response surface method (RSM) with quadratic expression was employed to derive an approximate surrogate model to map random variables to the first order natural frequency, as shown in Equation (8):

$$
g(\mathbf{X})=a+b_{i} \sum_{i=1}^{n} x_{i}+c_{i j} \sum_{i=1}^{n} x_{i} \sum_{i=1}^{n} x_{j}
$$

where $g$ represents the first order natural frequency, $x_{i}$ represents micro-scale or meso-scale random variable shown in Table 1 or Table 2, and $a, b$ and $c$ are regression terms. In this work, the regression terms were determined by central composite design method [31]. The central composite design was composed of one central point, two axis points per input variable and factorial points at the corners of the hypercube. Twenty-seven design points were employed for the meso-scale uncertainty scenario and 79 design points were employed for the micro-scale uncertainty scenario. In comparison to other experimental design methods such as the Box-Behnken method, the central composite design method 
could provide high quality predictions over the entire design space, and it is more flexible considering the number of input random variables [32].

For all laminate configurations shown in Table $3,1 \times 10^{5}$ group samples of random variables were drawn to conduct stochastic analysis based on the surrogate model derived by the RSM, and corresponding relative error on estimation of the mean value of first order natural frequency was less than $0.01 \%$ (calculated by Equation (6)). For the scenario of 'correlated meso-scale uncertainty', Gibbs sampling was employed to draw samples of meso-scale random variables to account for their correlation [21], by the procedure as follows:

(1) Initiation of random variable $x_{i}(i=1,2, \ldots, \mathrm{n})$;

(2) For $t=0,1,2, \ldots$, do the iterative sampling as follows:

1. $x_{1}^{(t+1)} \sim p\left(x_{1} \mid x_{2}^{t}, x_{3}^{t}, \cdots x_{n}^{t}\right)$

2. $x_{2}^{t+1} \sim p\left(x_{2} \mid x_{1}^{t+1}, x_{3}^{t}, \cdots x_{n}^{t}\right)$

3. $\quad \cdots \ldots . .$.

4. $x_{j}^{t+1} \sim p\left(x_{j} \mid x_{1}^{t+1}, \cdots, x_{j-1}^{t+1}, x_{j+1}^{t} \cdots x_{n}^{t}\right)$

5. $\quad \cdots \ldots \ldots$

6. $x_{n}^{t+1} \sim p\left(x_{n} \mid x_{1}^{t+1}, x_{2}^{t+1}, \cdots x_{n-1}^{t+1}\right)$

where $t$ denotes the number of sample, and $p()$ denotes probability density function.

Table 4 lists mean value and standard deviation of derived first order natural frequency of different laminate plates. It is seen that mean values of the first order natural frequency derived from the three different consideration of uncertainty were almost identical, with a difference less than $0.01 \%$. The standard deviations of the first order natural frequency derived from 'micro-scale uncertainty' and 'correlated meso-scale uncertainty' were also very similar, with a difference less than $2 \%$. This small difference could be introduced by the process of probabilistic density function fitting of meso-scale random variables. However, significant difference was seen between the standard deviation derived by 'independent meso-scale uncertainty' and 'correlated meso-scale uncertainty' or 'micro-scale uncertainty', where the standard deviation derived by 'independent meso-scale uncertainty' was around $10 \%$ larger.

Table 4. Statistics of first order natural frequencies of laminate plate (unit in $\mathrm{Hz}$ ).

\begin{tabular}{ccccccc}
\hline \multirow{2}{*}{ No. } & \multicolumn{2}{c}{ Micro-Scale } & \multicolumn{2}{c}{ Correlated Meso-Scale } & \multicolumn{2}{c}{ Independent Meso-Scale } \\
\cline { 2 - 7 } & Mean & Std & Mean & Std & Mean & Std \\
\hline Laminate 1 & 167.2 & 5.17 & 167.3 & 5.19 & 167.3 & $\begin{array}{c}5.61 \\
8.1 \% *\end{array}$ \\
\hline Laminate 2 & 181.0 & 5.89 & 181.0 & 6.00 & 181.0 & $\begin{array}{c}6.53 \\
8.8 \%\end{array}$ \\
\hline Laminate 3 & 290.5 & 8.12 & 290.5 & 8.25 & 290.7 & $\begin{array}{c}8.72 \\
\text { Laminate 4 }\end{array}$ \\
\hline 275.6 & 7.65 & 275.7 & 7.88 & 275.8 & $\begin{array}{c}8.88 \\
12.7 \%\end{array}$ \\
\hline
\end{tabular}

* Difference from its counterpart value of 'Correlated Meso-Scale'.

Figure 2 shows histogram and probability distribution of the first order natural frequency of Laminate 1 derived from 'independent meso-scale uncertainty' and 'correlated meso-scale uncertainty'. From the histogram shown in Figure 2a, it is shown that the 'correlated meso-scale uncertainty' provides more samples at the middle region and less samples at the tail region. By Kolmogorov-Smirnov and Anderson-Darling tests, the probability distribution of the first order natural frequency tended to follow normal distribution. From the fitted probability density function by normal distribution as shown 
in Figure $2 b$, it is seen that there is notable difference in the tail region between the two probability density functions. The cumulative probability of the first order natural frequency is shown in Figure 3, which shows that the 'independent meso-scale uncertainty' provides a notable overestimation on the cumulative probability. This demonstrates a necessity to account for statistical correlation between meso-scale uncertainty to derive accurate stochastic natural frequency.

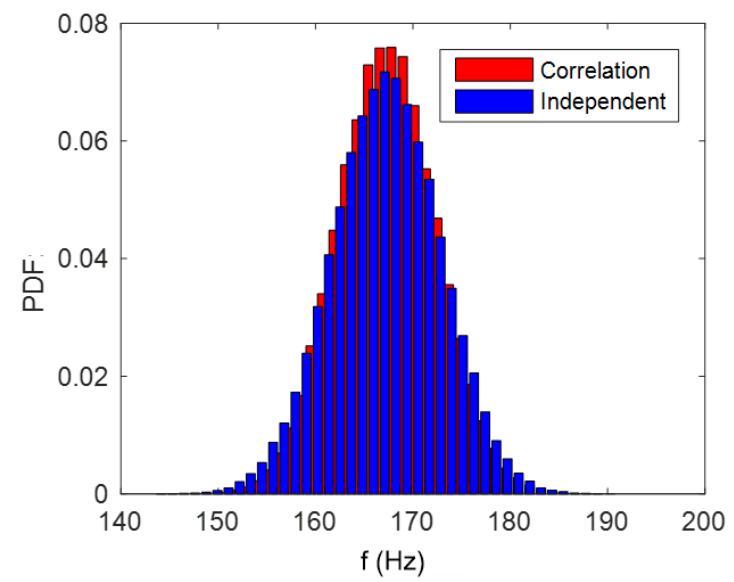

(a)

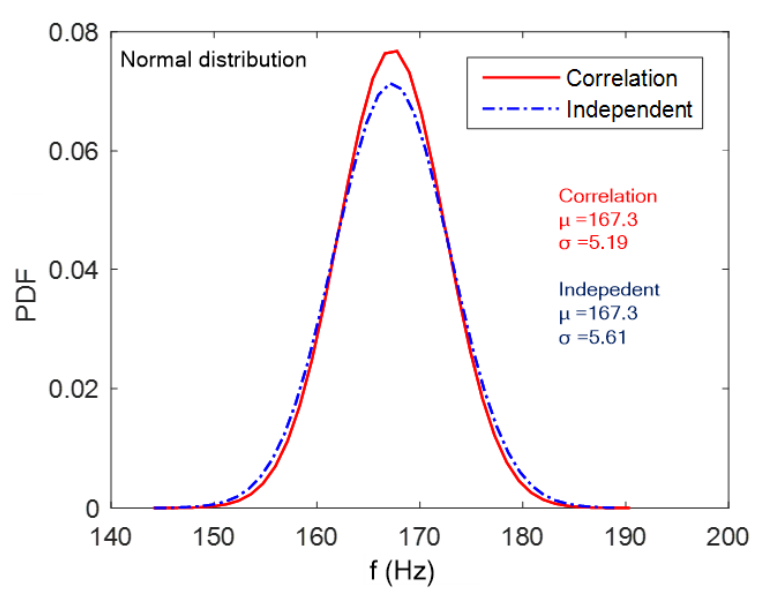

(b)

Figure 2. Probabilistic distribution of first order frequency of Laminate 1 by considering correlated and independent meso-scale random variables: (a) histogram; (b) fitted by normal distribution.

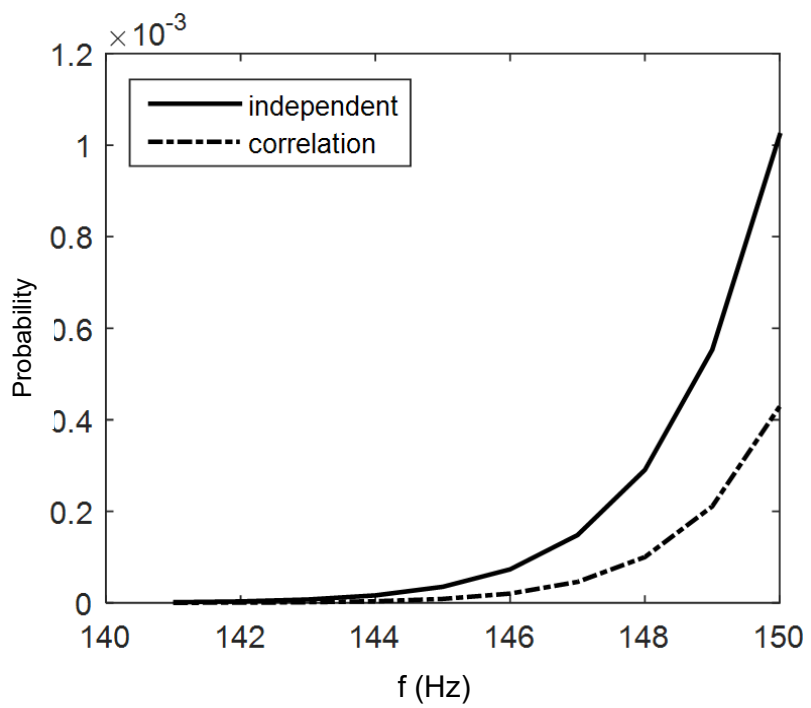

Figure 3. Cumulative probability of first order frequency of Laminate 1, derived by considering correlated and independent meso-scale random variables.

To achieve better understanding on the contribution of different uncertainty to the stochastic variation of the natural frequency, linear correlation coefficients between the first order natural frequency of Laminate 1 and meso-scale random variables were derived, as shown in Figure 4. The linear correlation coefficient reflected a stochastic dependence or sensitivity of stochastic variation of the natural frequency over input random variables. It is seen that neglecting correlation between meso-scale uncertainty suppressed the stochastic dependence on $E_{22}$ and $G_{12}$, which was similar to observation in [1] where stochastic deflection of a laminate structure was investigated. An interesting observation is on the dependence over laminate density. If the statistical correlation between the meso-scale input random variables was ignored, the stochastic dependence of the first order natural 
frequency over ply density was negative. It seems to be under expectation as it is known that larger density results into smaller natural frequency if plate stiffness and boundary conditions remain unchanged. However, from a multi-scale viewpoint, the ply density is actually positively correlated with ply modulus, and a larger ply density also indicates a larger stiffness. Hence, for the case of 'correlated meso-scale uncertainty', a positive correlation was seen between the natural frequency and the ply density. This highlights the importance to consider statistical correlation between meso-scale mechanical properties to achieve comprehensive understanding on the stochastic free vibration of laminate plates.

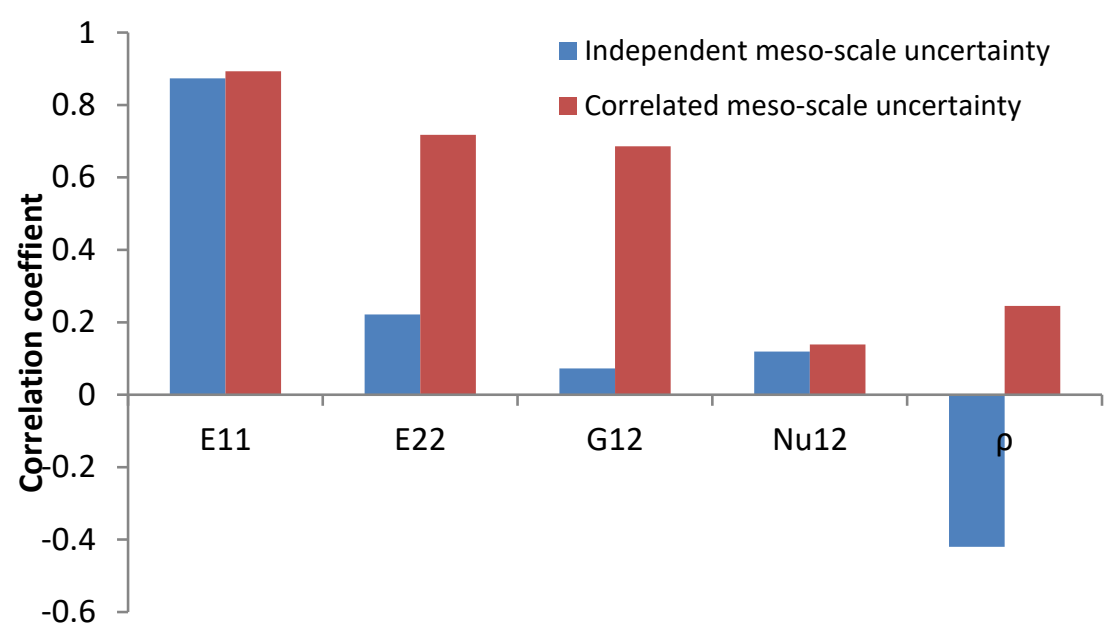

Figure 4. Linear correlation coefficient between first order natural frequency of laminate plate and meso-scale random variables.

For Laminates 2, 3 and 4 listed in Table 3, similar characteristics of the standard deviation, cumulative probability and sensitivity of the first order natural frequency were obtained as compared to Laminate 1, considering the discrepancy between the three different uncertainty considerations.

\subsection{Laminated Cylindrical Shell}

Laminated cylindrical shell structures are widely used in airspace, aerospace and energy engineering fields, with applications such as the dual launch system (SYLDA) and interstage skirt structure (ISS) of Ariane 5 launcher [33]. Especially, circular cut-outs are made on the laminated cylindrical shell of the SYLDA. In this section, stochastic natural frequency of a laminated cylindrical shell with circular cut-outs is investigated. The geometry of the laminated cylindrical shell is shown in Figure 5a, which was based on a scaled model of the SYLDA of Ariane 5 launcher where the shell diameter is equal to the shell length and the cut-out diameter is around 0.1-0.2 times of shell length. The laminate was set as eight-layered E-glass fibre/epoxy material, and the ply orientation was $( \pm \theta)_{4}$. A ply with an orientation at 0 indicates that fibre is aligned in the cylinder length direction. Ply thickness was selected as $0.45 \mathrm{~mm}$. Both ends of the laminated cylindrical shell were clamped. FE modeling was employed to obtain its first order natural frequency, as shown in Figure 5. The laminate was modeled by four-node linear-elastic shell element (Shell181 in Ansys 14.5), and a mesh size of $5 \times 5 \mathrm{~mm}$ was found to be fine enough to provide a convergent solution. FE solution on the first order vibration mode of $( \pm 45)_{4}$ laminate cylindrical shell is shown in Figure $5 \mathrm{~b}$.

Similar to the analysis of laminate plates in last section, a combination of RSM and Monte-Carlo simulation is adopted to obtain the statistics of the first order natural frequency, by considering 'micro-scale uncertainty', 'independent meso-scale uncertainty' and 'correlated meso-scale uncertainty'. The derived standard deviation of the first order natural frequency is shown in Figure 6. It is seen that the difference on the standard deviation between the three difference uncertainty consideration was fairly small for $\theta$ at $0^{\circ}, 30^{\circ}, 45^{\circ}$ and $60^{\circ}$. However, for the situation of $\theta=90^{\circ}$, the standard 
deviation derived from 'independent meso-scale uncertainty' was $10.4 \%$ larger than that of 'correlated meso-scale uncertainty' or 'micro-scale uncertainty'. This difference agrees with that of laminate plates shown in Table 4, which again demonstrates that ignoring the statistical correlation between meso-scale uncertainty probably leads to overestimation of the standard deviation of structure natural frequency.

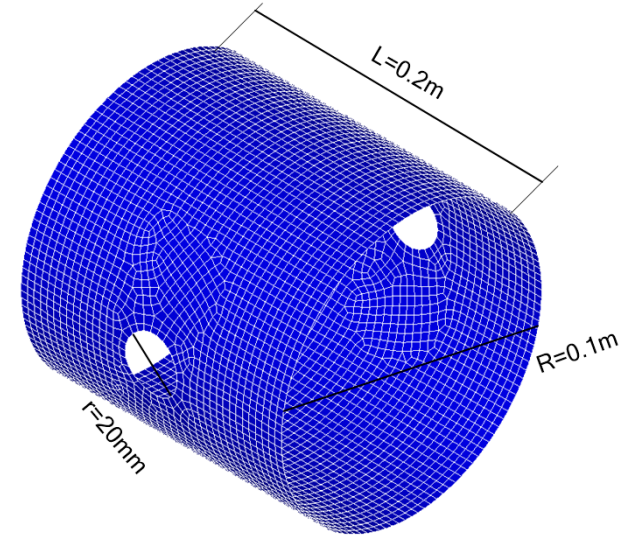

(a)

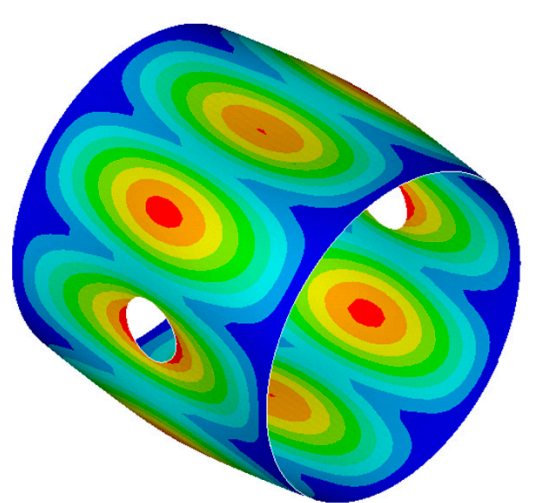

(b)

Figure 5. (a) Geometrical dimension and mesh of laminate cylindrical shell; (b) first order vibration model of $( \pm 45)_{4}$ laminate.

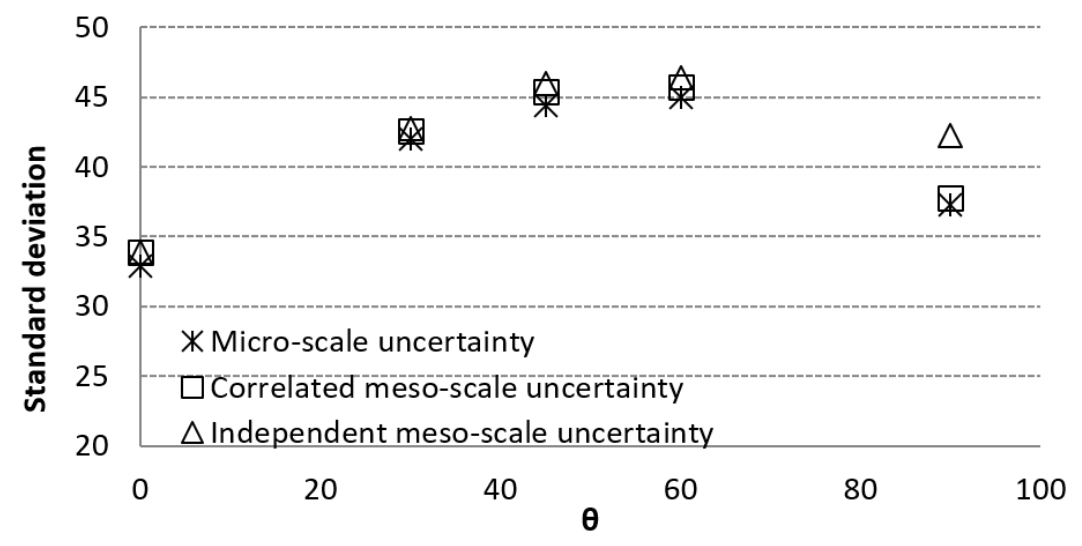

Figure 6. Standard deviation of first order natural frequency of $( \pm \theta)_{4}$ laminate cylindrical shell derived by considering different uncertainty.

\section{Discussion}

Fibre reinforced composite is essentially a type of multi-scale material. Uncertainty consideration from different scales would provide more comprehensive understanding on accurate uncertainty characterization. Previous work has highlighted possible existence of significant correlation between ply mechanical properties $[19,22]$. This correlation would affect reliability of composite structures considering structure failure defined by structure deformation, fracture or buckling [20]. It is known that natural frequency of composite structures not only depends on ply elastic properties but also laminate density. Therefore, as a new observation on the statistical correlation associated to ply density, it would be interesting to see how much the correlation contributes to the statistics of structure natural frequency. Here, a further comparison is conducted on deriving the statistics of structure natural frequency by considering two scenarios: (1) considering only correlation between ply mechanical properties $\left(E_{11}, E_{22}, G_{12}, v_{12}\right)$; (2) considering correlation between ply mechanical properties and also density $\left(E_{11}, E_{22}, G_{12}, v_{12}, \rho\right)$. The derived standard deviations of the first order natural frequency of Laminate 1 (see Table 3) and (90) 8 laminate cylindrical shell are shown in Table 5. It is interesting to observe that neglecting correlation associated with ply density results into $30-50 \%$ overestimation of 
the standard deviation, while neglecting all correlation between meso-scale uncertainty results into around $10 \%$ overestimation.

Table 5. Standard deviation of first order natural frequency considering different uncertainty.

\begin{tabular}{cccc}
\hline & $\begin{array}{c}\text { Meso-Scale Correlation } \\
\left(\boldsymbol{E}_{\mathbf{1 1}}, \boldsymbol{E}_{\mathbf{2 2}}, \boldsymbol{G}_{\mathbf{1 2}}, \boldsymbol{v}_{\mathbf{1 2}}, \boldsymbol{\rho}\right)\end{array}$ & $\begin{array}{c}\text { Meso-Scale Correlation } \\
\left(\boldsymbol{E}_{\mathbf{1 1}}, \boldsymbol{E}_{\mathbf{2 2}}, \boldsymbol{G}_{\mathbf{1 2}}, \boldsymbol{v}_{\mathbf{1 2}}\right)\end{array}$ & $\begin{array}{c}\text { Meso-Scale } \\
\text { Independent }\end{array}$ \\
\hline \multirow{2}{*}{$(0 / 90)_{8}$ plate } & $5.10 \mathrm{~Hz}$ & $6.70 \mathrm{~Hz}$ & $5.61 \mathrm{~Hz}$ \\
& - & $(31.4 \%)^{*}$ & $(10.0 \%)^{*}$ \\
\hline \multirow{2}{*}{$(90)_{8}$ cylindrical shell } & $37.8 \mathrm{~Hz}$ & $56.0 \mathrm{~Hz}$ & $42.2 \mathrm{~Hz}$ \\
& - & $(48.2 \%)^{*}$ & $(11.6 \%)^{*}$ \\
\hline
\end{tabular}

${ }^{*}$ Difference from its counterpart value of 'meso-scale correlation $\left(E_{11}, E_{22}, G_{12}, v_{12}, \rho\right)$ '.

Overestimation of standard deviation by $30-50 \%$ would lead to very large error in corresponding cumulative probability estimation. Therefore, it is important to account for the statistical correlation associated with ply density to obtain accurate stochastic free vibration behaviour of laminated structures.

A recent study [25] reports that larger standard deviation of natural frequency was obtained for the case of 'micro-scale uncertainty' than that of the 'independent meso-scale uncertainty', which seems to contradict with our observations in Table 4 and Figure 5. Actually, the comparison in [25] was conducted by assuming identical coefficient of variation $(\mathrm{CoV})$ for both meso-scale and micro-scale uncertainties, for example the $\mathrm{CoV}$ of all of meso-scale and micro-scale random variables were assumed to be $5 \%$. However, Tables 1 and 2 tell that micro-scale uncertainty with $\mathrm{CoV}$ at $5 \%$ actually results in $\mathrm{CoV}$ of meso-scale uncertainty at around $10 \%$. The uncertainty amplification from micro-scale to meso-scale was also addressed in [18]. The uncertainty amplification explains why larger standard deviation was obtained for the case of 'micro-scale uncertainty' in [25]. Meanwhile, statistical correlation between meso-scale uncertainty was not considered and discussed in [25].

\section{Conclusions}

The present study provides statistical natural frequency of composites structures derived from micro-scale and meso-scale uncertainty, for the circumstance composite structures are composed of plies with unidirectional fibre reinforcement. Meso-scale uncertainty is obtained from micro-scale uncertainty by a combination of Monte-Carlo simulation and bridging micromechanical model. It is observed that significant statistical correlation may not only exist between ply elastic properties but also associated with ply density. The statistical correlation between meso-scale physical properties is commonly ignored in current study on stochastic free vibration of composite structures. Comparison is conducted on natural frequency statistics of composite plates and cylindrical shell considering 'micro-scale uncertainty', 'correlated meso-scale uncertainty' and 'independent meso-scale uncertainty'. Several conclusions are drawn as follows:

1. Natural frequency statistics of composite structures could be reasonably derived from either micro-scale random variables or meso-scale random variables but their statistical correlation needs to be well characterised;

2. Ignoring the statistical correlation between meso-scale uncertainty may result in large overestimation of standard deviation of structure natural frequency;

3. If the natural frequency statistics of composite structures are calculated by meso-scale uncertainty, it is especially important to consider the statistical correlation associated with ply density, which is somehow not noticed by previous studies. It also shows that dependence of the stochastic variation of natural frequency over ply density is positive rather than negative.

It is very important to achieve accurate statistics of structure natural frequency in engineering design, so that potential structure resonance could be well avoided. Therefore, this work further 
suggests establishing standard experimental approaches to obtain statistical correlation between ply elastic properties and ply density.

Author Contributions: Conceptualization, S.Z. and X.C.; methodology, S.Z.; software, S.Z.; formal analysis, S.Z.; investigation, S.Z. and X.C.; writing—original draft preparation, S.Z.; writing—review and editing, X.C.; funding acquisition, S.Z.

Funding: This research was funded by National Natural Science Foundation of China, grant number 51405501.

Conflicts of Interest: The authors declare no conflict of interest.

\section{References}

1. Mustafa, G.; Suleman, A.; Crawford, C. Probabilistic micromechanical analysis of composite material stiffness properties for a wind turbine blade. Compos. Struct. 2015, 131, 905-916. [CrossRef]

2. Hwang, T.-K.; Hong, C.-S.; Kim, C.-G. Probabilistic deformation and strength prediction for a filament wound pressure vessel. Compos. Part B Eng. 2003, 34, 481-497. [CrossRef]

3. Chen, N.Z.; Sun, H.H.; Soares, C.G. Reliability analysis of a ship hull in composite material. Compos. Struct. 2003, 62, 59-66. [CrossRef]

4. Frangopol, D.M.; Recek, S. Reliability of fiber-reinforced composite laminate plates. Probab. Eng. Eng. Mech. 2003, 18, 119-137. [CrossRef]

5. Chamis, C.C.; Abumeri, G.H. Probabilistic dynamic buckling of composite shell structures. Compos. Part A Appl. Sci. Manuf. 2005, 36, 1368-1380. [CrossRef]

6. Ganesan, R.; Kowda, V.K. Buckling of composite beam-columns with stochastic properties. J. Reinf. Plast. Compos. 2005, 24, 513-543. [CrossRef]

7. Fan, Z.; Jiang, Y.; Zhang, S.; Chen, X. Experimental research on vibration fatigue of cfrp and its influence factors based on vibration testing. Shock Vib. 2017, 2017, 18. [CrossRef]

8. Chiachio, M.; Chiachio, J.; Rus, G. Reliability in composites-A selective review and survey of current development. Compos. Part B Eng. 2012, 43, 902-913. [CrossRef]

9. Oh, D.H.; Librescu, L. Free vibration and reliability of composite cantilevers featuring uncertain properties. Reliab. Eng. Syst. Safe. 1997, 56, 265-272. [CrossRef]

10. Dey, S.; Mukhopadhyay, T.; Adhikari, S. Stochastic free vibration analysis of angle-ply composite plates-A rs-hdmr approach. Compos. Struct. 2015, 122, 526-536. [CrossRef]

11. Dey, S.; Naskar, S.; Mukhopadhyay, T.; Gohs, U.; Spickenheuer, A.; Bittrich, L.; Sriramula, S.; Adhikari, S.; Heinrich, G. Uncertain natural frequency analysis of composite plates including effect of noise-A polynomial neural network approach. Compos. Struct. 2016, 143, 130-142. [CrossRef]

12. Chakraborty, S.; Mandal, B.; Chowdhury, R.; Chakrabarti, A. Stochastic free vibration analysis of laminated composite plates using polynomial correlated function expansion. Compos. Struct. 2016, 135, 236-249. [CrossRef]

13. Tawfik, M.E.; Bishay, P.L.; Sadek, E.A. Neural network-based second order reliability method (nnbsorm) for laminated composite plates in free vibration. Comp. Model. Eng. Sci. 2018, 115, 105-129.

14. Yin, Q.; Lardeur, P.; Druesne, F. Performances assessment of the modal stability procedure for the probabilistic free vibration analysis of laminated composite structures. Compos. Struct. 2018, 203, 474-485. [CrossRef]

15. Singh, B.N.; Yadav, D.; Iyengar, N.G.R. Free vibration of composite cylindrical panels with random material properties. Compos. Struct. 2002, 58, 435-442. [CrossRef]

16. Tripathi, V.; Singh, B.N.; Shukla, K.K. Free vibration of laminated composite conical shells with random material properties. Compos. Struct. 2007, 81, 96-104. [CrossRef]

17. Sriramula, S.; Chryssanthopoulos, M.K. Quantification of uncertainty modelling in stochastic analysis of frp composites. Compos. Part A Appl. Sci. Manuf. 2009, 40, 1673-1684. [CrossRef]

18. Rollet, Y.; Bonnet, M.; Carrère, N.; Leroy, F.H.; Maire, J.F. Improving the reliability of material databases using multiscale approaches. Compos. Sci. Technol. 2009, 69, 73-80. [CrossRef]

19. Shaw, A.; Sriramula, S.; Gosling, P.D.; Chryssanthopoulos, M.K. A critical reliability evaluation of fibre reinforced composite materials based on probabilistic micro and macro-mechanical analysis. Compos. Part B Eng. 2010, 41, 446-453. [CrossRef] 
20. Zhang, S.; Zhang, C.; Chen, X. Effect of statistical correlation between ply mechanical properties on reliability of fibre reinforced plastic composite structures. J. Compos. Mater. 2015, 49, 2935-2945. [CrossRef]

21. Zhang, S.; Zhang, L.; Wang, Y.; Tao, J.; Chen, X. Effect of ply level thickness uncertainty on reliability of laminated composite panels. J. Reinf. Plast. Compos. 2016, 35, 1387-1400. [CrossRef]

22. Zhang, S.; Wang, H.; Zhang, L.; Chen, X. Statistical correlation between elastic properties of plain-weave composite and its influence on structure reliability. Compos. Struct. 2018, 200, 939-945. [CrossRef]

23. Zhou, X.Y.; Gosling, P.D.; Ullah, Z.; Kaczmarczyk, Ł.; Pearce, C.J. Exploiting the benefits of multi-scale analysis in reliability analysis for composite structures. Compos. Struct. 2016, 155, 197-212. [CrossRef]

24. Zhou, X.Y.; Gosling, P.D.; Ullah, Z.; Kaczmarczyk, L.; Pearce, C.J. Stochastic multi-scale finite element based reliability analysis for laminated composite structures. Appl. Math. Model. 2017, 45, 457-473. [CrossRef]

25. Naskar, S.; Mukhopadhyay, T.; Sriramula, S.; Adhikari, S. Stochastic natural frequency analysis of damaged thin-walled laminated composite beams with uncertainty in micromechanical properties. Compos. Struct. 2017, 160, 312-334. [CrossRef]

26. Mounier, D.; Poilâne, C.; Bûcher, C.; Picart, P. Evaluation of transverse elastic properties of fibers used in composite materials by laser resonant ultrasound spectroscopy. In Proceedings of the 11th Congrès Français d'Acoustique (Acoustics 2012), Nantes, France, 23-27 April 2012; Available online: https://hal.archivesouvertes.fr/hal-00811303/document (accessed on 6 June 2019).

27. Sanei, S.H.R.; Fertig Iii, R.S. Length-scale dependence of variability in epoxy modulus extracted from composite prepreg. Polym. Test 2016, 50, 297-300. [CrossRef]

28. Huang, Z. Micromechanical prediction of ultimate strength of transversely isotropic fibrous composites. Int. J. Solids Struct. 2001, 38, 4147-4172. [CrossRef]

29. Rubinstein, R.Y.; Kroese, D.P. Simulation and the Monte Carlo Method, 2nd ed.; John Wiley \& Sons: Hoboken, NJ, USA, 2007.

30. Soden, P.D.; Hinton, M.J.; Kaddour, A.S. Lamina properties, lay-up configurations and loading conditions for a range of fibre-reinforced composite laminates. Compos. Sci. Technol. 1998, 58, 1011-1022. [CrossRef]

31. Anderson, M.J.; Whitcomb, P.J. RSM simplified: Optimizing Processes Using Response Surface Methods for Design of Experiments, 2nd ed.; Taylor \& Francis Group: London, UK, 2016.

32. Reh, S.; Beley, J.-D.; Mukherjee, S.; Khor, E.H. Probabilistic finite element analysis using ansys. Struct. Saf. 2006, 28, 17-43. [CrossRef]

33. Alfano, M.; Bisagni, C. Probability-based methodology for buckling investigation of sandwich composite shells with and without cut-outs. Int. J. Comput. Meth. Eng. Sci. Mech. 2017, 18, 77-90. [CrossRef] 